\title{
INSIDE THE CRYSTAL BALL: NEW APPROACHES TO PREDICTING THE GASOLINE PRICE AT THE PUMP
}

\author{
CHRISTIANE BAUMEISTER ${ }^{\mathrm{a}, \mathrm{b}}$, LUTZ KILIAN ${ }^{\mathrm{b}, \mathrm{c} *}$ AND THOMAS K. LEE \\ ${ }^{a}$ Department of Economics, University of Notre Dame, Notre Dame, IN, USA \\ ${ }^{\mathrm{b}}$ CEPR \\ ${ }^{\mathrm{c}}$ Department of Economics, University of Michigan, CEPR, Ann Arbor, MI, USA \\ ${ }^{\mathrm{d}}$ US Energy Information Administration, Washington, DC, USA
}

\begin{abstract}
SUMMARY
Appropriate real-time forecasting models for the US retail price of gasoline yield substantial reductions in the mean-squared prediction error (MSPE) at horizons up to 2 years as well as substantial increases in directional accuracy. Even greater MSPE reductions are possible by constructing a pooled forecast that assigns equal weight to five of the most successful forecasting models. Pooled forecasts have lower MSPE than the US Energy Information Administration gasoline price forecasts and the gasoline price expectations in the Michigan Survey of Consumers. We also show that as much as 39\% of the decline in gas prices between June and December 2014 was predictable. Copyright $\odot 2016$ John Wiley \& Sons, Ltd.
\end{abstract}

Received 9 May 2015; Revised 5 December 2015

Supporting information may be found in the online version of this article. This file can also be downloaded at http://qed.econ.queensu.ca/jaelforthcoming/baumeister-kilian-lee

\section{INTRODUCTION}

There is arguably no retail price in the US economy that is more closely watched than the price of gasoline. ${ }^{1}$ Fluctuations in gasoline prices not only directly affect the pocketbook of consumers, but also affect which cars consumers choose to buy and how close they choose to live to their workplace. Gasoline prices even have been shown to affect home prices and home foreclosure rates (see Hamilton, 2009; Molloy and Shan, 2013). Central bankers in turn are concerned with the effects of gasoline prices on inflation expectations, consumer spending and consumer confidence (see, for example, Yellen, 2011). Being able to predict the price of gasoline matters not only to consumers, automobile manufacturers and central bankers; gasoline price forecasts also help predict the revenue from ad valorem gasoline taxes, and they are considered useful more generally for assessing the outlook for inflation and economic growth. Finally, gasoline price predictions play an important role in microeconomic models of the automobile market and in the analysis of environmental policies (see, for example, Busse et al., 2012, 2013; Allcott and Wozny, 2014).

The EIA issues regular forecasts of the monthly and quarterly US retail price of gasoline that are closely monitored and widely discussed by the media. Such monthly or quarterly forecasts are useful for both macroeconomic and microeconomic analysis. The EIA is not the only producer of gasoline price forecasts, however. For example, the Michigan Survey of Consumers regularly inquires about consumers' expectations about future US retail gasoline prices (see Anderson et al., 2013). Perhaps

\footnotetext{
* Correspondence to: Lutz Kilian, CEPR and Department of Economics, University of Michigan, Ann Arbor, MI, USA.

E-mail: 1kilian@umich.edu

${ }^{1}$ Gasoline in the UK is referred to as petrol (which is short for 'petroleum'). We refer to gasoline throughout this paper because the standard definition of the term petroleum also includes crude oil and refined products other than gasoline. For example, the US Energy Information Administration (EIA), which is the primary source for global energy market data, defines petroleum as a class of liquid hydrocarbon mixtures including crude oil, lease condensate, unfinished oils, natural gas plant liquids and refined products obtained from the processing of crude oil such as heating oil, diesel, gasoline, kerosine, bunker fuel or jet fuel.
} 
surprisingly, the accuracy of retail gasoline price forecasts has not received much attention by academic researchers. One recent exception is Anderson et al. (2011). This study investigates the ability of US consumers to forecast the price of gasoline, as measured by responses in the Michigan Survey of Consumers. Another exception is an evaluation of the accuracy of EIA gasoline price forecasts by Sanders et al. (2009). Neither study, however, addresses the question of how to construct gasoline price forecasts. There are a number of model-free methods and regression-based methods that can be used for constructing gasoline price forecasts. The literature has largely ignored these methods to date. ${ }^{2}$ One reason may have been the perception that forecasting gasoline prices beyond a few days is next to impossible, given publicly available information. In this view, there is no rhyme or reason to privatesector gasoline price forecasts, and for all practical purposes we can think of the current gasoline price as the best predictor of the future price. Indeed, many energy and environmental economists have considered the current real price of gasoline a reasonable benchmark for modeling expectations about the future real price of gasoline (see, for example, Kahn, 1986; Li et al., 2009; Busse et al., 2013; Langer and Miller, 2013; Allcott and Wozny, 2014).

Until recently, the no-change forecast (or random walk forecast) was also considered the best possible forecast of the price of crude oil, but a rapidly expanding literature has overturned this consensus. It is well established now that one can forecast the price of crude oil in real time more accurately than the no-change forecast. ${ }^{3}$ Because gasoline is a product obtained from refining crude oil, US gasoline prices are closely tied to the evolution of the price of crude oil, with both prices moving together in the long run (see, for example, Kilian, 2010). Hence one might expect the ability to forecast oil prices to extend to gasoline price forecasts, but such a conclusion is less than obvious upon reflection. Unlike oil prices, gasoline prices are subject to changes in gasoline taxes and environmental regulations and are affected by refinery shutdowns as a result of routine maintenance, accidents and hurricanes (see, for example, Kilian, 2010). Moreover, the link between oil and gasoline prices has been affected by important changes in the structure of the refining market in recent years (see, for example, Borenstein and Kellogg, 2014; Kilian, 2016). Finally, the evolution of gasoline prices is also affected by changes in the market power of refiners (see, for example, Borenstein and Shepard, 2002; Gilbert and Hastings, 2005; Sweeney, 2015).

The existence of these additional gasoline-market-specific determinants of the price of gasoline does not mean that we should actually forecast these determinants, which often are essentially unpredictable (such as in the case of refinery fires) or have effects that are too complicated to model in a real-time setting (such as the effects of Californian environmental regulations on national US gasoline markets). It does raise questions, however, about the forecasting ability of models based on aggregate oil market and gasoline market data that do not explicitly incorporate the microeconomic structure of gasoline markets. Our analysis shows that, these complications notwithstanding, forecasting models based only on aggregate data for the gasoline and crude oil market can be useful.

We provide a comprehensive analysis of the forecastability of the real US price of gasoline, drawing on state-of-the-art regression-based forecasting methods. Our objective is to provide a benchmark for future studies and to document the merits of alternative forecasting models. The analysis is conducted in real time, taking account of the delays in the availability of some data and subsequent revisions when data become available. We focus on the problem of forecasting the average monthly US retail price of gasoline, as defined by the EIA, at horizons up to 24 months (or eight quarters).

\footnotetext{
2 A rare exception is the work of Bastianin et al. (2014), which in turn builds on preliminary analysis in Bachmeier and Griffin (2003). Bastianin et al. investigate the extent to which allowing for asymmetries in the relationship between oil and gasoline prices improves the accuracy of regression-based forecasts for the price of gasoline. These studies, however, are not concerned with the question of whether either model forecasts more accurately than the no-change forecast or how they compare with other forecasts.

${ }^{3}$ Examples include Alquist et al. (2013), Baumeister et al. (2015), Baumeister and Kilian (2012, 2014a, 2015), Baumeister et al. (2014), Bernard et al. (2016) and Chen (2014).
} 
Our analysis addresses several questions. First, we examine the accuracy of forecasts of the retail gasoline price based only on its own past. We consider autoregressive, autoregressive-moving average and exponential smoothing forecasts. Second, we quantify the predictive content of financial market variables such as gasoline futures prices or the spread between the gasoline spot price and the spot price of crude oil. Third, we investigate the predictive power of bivariate vector autoregressive (VAR) models including both retail gasoline prices and crude oil prices. Our analysis examines in detail the impact of the lag structure, of imposing cointegration restrictions on the VAR model and of the definition of the price of crude oil. We abstract from asymmetric VAR models, given the evidence provided by Bachmeier and Griffin (2003) and Bastianin et al. (2014) in favor of the linear VAR model. Fourth, we consider models of the gasoline market linking gasoline prices to changes in US gasoline consumption. We also explore the use of single-equation factor forecasting models and of factoraugmented VAR (FAVAR) forecasting models linking the price of gasoline to US real economic activity. Fifth, building on recent developments in the literature on oil market forecasting models, we explore larger-scale VAR models that jointly model the global market for crude oil and the US gasoline market.

Our key finding is that substantial reductions in the mean-squared prediction error (MSPE) of gasoline price forecasts are feasible in real time at horizons up to 2 years, as are substantial increases in directional accuracy. The most accurate individual model is a simple bivariate VAR(1) model for real retail gasoline and Brent crude oil prices. This model generates MSPE reductions at all horizons ranging from $10 \%$ to $26 \%$ and at some horizons has statistically significant directional accuracy as high as $68 \%$. These results are robust to the use of Bayesian estimation methods as proposed in Giannone et al. (2015). Even more reliable overall is a pooled forecast that assigns equal weight to the five most successful individual forecasting models. The accuracy of this pooled forecast also is more stable over time than that of the VAR(1) model. Moreover, the implied nominal gasoline price forecast has lower MSPE than the gasoline price forecasts of the US EIA and the gasoline price expectations in the Michigan Survey of Consumers. Finally, we show that as much as $39 \%$ of the widely discussed decline in the retail price of gasoline after June 2014 was predictable, but only when using a VAR model of the global market for crude oil augmented with the US price of gasoline.

The remainder of the paper is organized as follows. Section 2 reviews the forecasting environment and discusses the gasoline price data. In Section 3 we motivate and describe each of the alternative forecasting methods and discuss their performance. Section 4 provides additional sensitivity analysis. We assess the role of seasonality in the monthly gasoline price data, assess the stability over time of the accuracy of our preferred gasoline price forecast, examine the potential benefits from pooling the most successful forecasting models, and we extend the analysis to quarterly forecasts. Section 5 discusses how to recover nominal price forecasts from real gasoline price forecasts. We compare the pooled forecast with the gasoline price expectations in the Michigan Survey of Consumers and with quarterly EIA forecasts of the nominal price of gasoline. In Section 6 we investigate how much of the recent decline in gasoline prices was predictable as of the end of June 2014. The concluding remarks are in Section 7. Figures A1 and A2 and Tables A1-A8 can be found in the online Appendix.

\section{THE FORECASTING ENVIRONMENT}

All forecasting models are estimated at monthly frequency. We consider monthly forecast horizons up to 2 years. Forecasts at the corresponding quarterly horizons are obtained by averaging the monthly forecasts at quarterly frequency, as recommended in Baumeister and Kilian (2014a). The regression models underlying the gasoline price forecasts are re-estimated recursively in real time, as more data become available. This approach has been shown in the oil price forecasting literature to be much more accurate than relying on rolling regressions (see, for example, Baumeister and Kilian, 2014a). Our 
analysis is conducted in real time, taking account of the delays in the availability of some data and of subsequent revisions when data become available.

\subsection{Real-Time Data}

We rely on data from a suitably updated real-time database developed in Baumeister and Kilian (2012, 2014a) and extended in Baumeister et al. $(2014,2016)$. The reader is referred to these references for a detailed description of the data sources and definitions. This database consists of different datasets for each month in the sample. Each dataset is referred to as a vintage and contains only the data that were known to the forecaster at each point in time. Missing observations at the end of each dataset are nowcast based on data in this vintage.

We add to this database real-time data for US gasoline consumption and for the nominal volumeweighted average US retail price of gasoline. The price of gasoline is reported in column 4 of Table 9.4 of the Monthly Energy Review. This gasoline price series is backcast from January 1978 to October 1973 using EIA data on the price of leaded regular gasoline, as in Kilian (2010). There are no revisions of the nominal gasoline price data, but there is a delay in their release. We nowcast the missing observations at the end of each vintage based on the monthly average of the weekly releases of the nominal retail gasoline price in the Weekly Petroleum Status Report. Gasoline consumption data are constructed as the sum of commercial, industrial and transportation sales, following Kilian (2010). Gasoline consumption data are subject to revisions. The real-time data were manually compiled from past issues of the Monthly Energy Review. Percent changes in gasoline consumption were nowcast at their average rate of growth in the preceding 5 years based on a moving-average model, taking into account seasonal variation in the form of seasonal dummies.

\subsection{Evaluation Criteria}

The evaluation period is January 1992 to March 2014 (or equivalently the first quarter of 1992 to the first quarter of 2014). The length of the initial recursive estimation period differs depending on data availability. No data prior to October 1973 are used in estimation. Our objective is to forecast the level of the ex post revised real price of gasoline, as measured by the observations in the September 2014 vintage of the real-time database.

The real-time forecasts are evaluated based on their recursive MSPE and based on their directional accuracy, which is of independent interest for many economic decisions. For example, the Michigan Survey of Consumers explicitly asks households whether they expect gasoline prices to go up or down in addition to inquiring about point forecasts. Directional accuracy is measured by the success ratio. The success ratio is the fraction of times that a method correctly predicts the direction of change in the real price of gasoline. Success ratios above 0.5 indicate an improvement relative to the no-change forecast. For expository purposes and to facilitate comparisons with other studies, the MSPE results are normalized relative to the no-change forecast, with a ratio below 1 indicating a gain in accuracy. Where appropriate, we assess the statistical significance of the MSPE reductions based on the test of Diebold and Mariano (1995) for non-nested models without estimation uncertainty. We also examine the stability of our results across horizons, across specifications and over time. The statistical significance of the success ratios is assessed based on the test proposed in Pesaran and Timmermann (2009).

\section{FORECAST EVALUATION}

This section provides a systematic evaluation of the accuracy of forecasting methods for the monthly retail price of gasoline. We focus on forecasts of the real price of gasoline because for many economic 
questions it is the real price rather than the nominal price that matters. Moreover, many of our forecasting models are motivated by economic models relating to the determination of the real price of gasoline. ${ }^{4}$ The question of how to construct quarterly forecasts is addressed in Section 4; extensions to nominal gasoline price forecasts are discussed in Section 5. Before considering forecasting models motivated based on economic theory, it is useful to assess the forecast accuracy of simple time series models for the real price of gasoline.

\subsection{Forecasting the Real Retail Price of Gasoline Based on its Own Past}

It is well established that parsimonious autoregressive moving average (ARMA) time series models often provide more accurate forecasts than multi-equation forecasting models (see Box and Jenkins, 1970). A natural starting point is the $\operatorname{ARMA}(1,1)$ model for the real price of gasoline in logs, $r_{t}^{\text {gas }}$, with logs denoted by lower-case letters. The ARMA $(1,1)$ model is estimated by the method of maximum likelihood. Forecasts $\hat{r}_{t+h \mid t}^{\text {gas }}$ of the log of the real price of gasoline are constructed iteratively from the estimated ARMA model conditional on the most recent data and converted to levels, $\hat{R}_{t+h \mid t}^{\text {gas }}$, with upper-case denoting dollar prices, resulting in the forecast $\hat{R}_{t+h \mid t}^{\text {gas }}=\exp \left(\hat{r}_{t+h \mid t}^{\text {gas }}\right)$, where $h$ is the forecast horizon. The first column of Table A1 shows that this ARMA $(1,1)$ model has systematically higher MSPE than the no-change forecast and cannot be recommended.

One concern with this specification is that we cannot rule out a priori that the log of the real price of gasoline is a unit root process because this process appears highly persistent (see Figure A1). Indeed, a unit root test would not be able to reject the null of a unit root, suggesting that an alternative specification of the model as an MA(1) process in percent changes (IMA(1)) may be more appropriate (see Diebold and Kilian, 2000). The second column of Table A1 demonstrates that this alternative specification obtained by imposing the unit root on the ARMA $(1,1)$ process, if anything, has even higher MSPE ratios. This evidence suggests that the process actually is not well characterized as a unit root process or near unit root process, mirroring similar results for the price of crude oil in Alquist et al. (2013). Finally, relaxing the dynamic specification by specifying an ARMA(1,1) model in first differences (ARIMA $(1,1)$ ) further increases the MSPE ratios. Apart from some directional accuracy at horizon 1 for all three specifications, none of these ARMA models is able to beat the random walk benchmark. This evidence adds credence to the view that standard time series forecasting models that perform well in a wide range of macroeconomic applications are not suitable for forecasting the real price of gasoline.

An alternative approach is to rely on purely autoregressive forecasting models for the log-level of the real price of gasoline. Forecasts are constructed iteratively and converted to levels according to $\hat{R}_{t+h \mid t}^{\mathrm{gas}}=$ $\exp \left(\hat{r}_{t+h \mid t}^{\text {gas }}\right)$. Autoregressive models may be estimated by unconstrained least-squares methods or by Bayesian shrinkage estimation methods. Bayesian shrinkage estimators allow the forecaster to reduce the variance of the forecast at the cost of increasing its bias. These methods have been shown to be successful in reducing the MSPE of autoregressive forecasts in a wide range of macroeconomic applications. Our application relies on state-of-the-art data-driven Bayesian forecasting methods that only rely on real-time information (see Giannone et al., 2015).

\footnotetext{
4 Throughout the paper all real prices are obtained by deflating the nominal price by the seasonally adjusted US consumer price index for all urban consumers. Real-time data for the monthly seasonally adjusted US consumer price index for all urban consumers can be obtained from the Economic Indicators published by the Council of Economic Advisers. These data are available in the FRASER database of the Federal Reserve Bank of St Louis. Additional real-time US consumer price index data were obtained from the macroeconomic real-time database of the Federal Reserve Bank of Philadelphia.
} 
An important question in specifying autoregressive (AR) or Bayesian autoregressive (BAR) models is the lag order. BAR models are likely to be preferable when working with less parsimonious models with many autoregressive lags. Table A1 shows results based on a fixed lag order of 12 , which has also been shown to work well in forecasting the real price of oil (see Alquist et al., 2013). Further analysis revealed that allowing for larger fixed lag orders or, for that matter, reducing the lag order, does not improve on this baseline model. Table A1 shows that this model, with the exception of horizon 6, produces no reductions in the MSPE compared to the no-change forecast, although it shows some signs of significant directional accuracy at horizons up to 18 months. There is little difference between the AR(12) and BAR(12) specification. An alternative approach to lag order selection is to select the lag order of the forecasting model at each point in time, allowing the lag order to vary across the recursive sample. We follow standard practice in choosing the lag order based on the Akaike information criterion (see, for example, Marcellino et al., 2006). Table A1 indicates that this approach produces similar results to the model with fixed lag order.

A very different forecasting approach is recursive exponential smoothing. Exponential smoothing involves converting the observed series, $\left\{r_{t}^{\text {gas }}\right\}_{t=1}^{T}$, into a smoothed series $\left\{\bar{r}_{t}^{\text {gas }}\right\}_{t=1}^{T}$. Forecasts are formed as $\hat{r}_{T+h \mid T}^{\text {gas }}=\bar{r}_{T}^{\text {gas }}$ and converted to levels by exponentiating. It can be shown that exponential smoothing delivers a one-sided moving average model with exponentially declining weights. This approach is designed for series that are not trending over time. Because the log-level of the real price of gasoline in Figure A1 has no pronounced trend, it is a natural candidate for the application of exponential smoothing. Given $\bar{r}_{1}^{\text {gas }}=r_{1}^{\text {gas }}$, the smoothed series is constructed recursively from

$$
\bar{r}_{t}^{\mathrm{gas}}=(1-a) r_{t}^{\mathrm{gas}}+a r_{t-1}^{\mathrm{gas}}, \quad t=2, \ldots, T
$$

where the smoothing parameter $a \in[0,1]$. The larger $a$, the smoother is $\bar{r}_{t}^{\text {gas }}$. For econometric applications, it is common to choose large values of $a$ (see, for example, Faust and Wright 2013). The results in Table A1 are based on $a=0.8$. The qualitative results are reasonably robust to changing this parameter.

One would expect the exponential smoothing forecasts of the real price of gasoline to perform well at longer horizons if there is some mean reversion in the real price of gasoline. Such mean reversion would be consistent, for example, with temporary gasoline supply shortages or with transitory shifts in demand for crude oil. The second-to-last column of Table A1 confirms that exponential smoothing performs very poorly at horizons 1 and 3 , but it greatly improves on the accuracy of the no-change forecast at longer horizons. The MSPE reductions at these horizons range from $8 \%$ to $22 \%$, depending on the horizon. Because exponential smoothing forecasts are not subject to estimation uncertainty, the statistical significance of the MSPE reductions can be assessed using the test of Diebold and Mariano (1995). Table A1 shows that several of the MSPE reductions are statistically significant at the 5\% level or the $10 \%$ level. Exponential smoothing forecasts have no directional accuracy, however, at any horizon.

The last column focuses on an unobserved components stochastic volatility (UC-SV) forecasting model. This UC-SV model was originally proposed by Stock and Watson (2007) in the context of forecasting inflation. The model treats the log of the real retail price of gasoline as the sum of a permanent component and a serially uncorrelated transitory component. Both components are allowed to be timevarying, making the model equivalent to a time-varying IMA(1) model for the growth rate of the real price of gasoline. Rather than using the Kalman filter, the model is estimated using the efficient Markov chain Monte Carlo (MCMC) sampler proposed in Chan (2013), building on Chan and Jeliazkov (2009). We adopt the same diffuse prior specification as Chan (2013). ${ }^{5}$

\footnotetext{
${ }^{5}$ More formally, let $r_{t}^{\text {gas }}=\tau_{t}+\eta_{t}$, where $\eta_{t}=\sigma_{\eta, t} \zeta_{\eta, t}$ is the transitory component and the stochastic trend component, $\tau_{t}$, evolves according to $\tau_{t}=\tau_{t-1}+\varepsilon_{t}$, where $\varepsilon_{t}=\sigma_{\varepsilon, t} \zeta_{\varepsilon, t}$. The log-variances of $\eta_{t}$ and $\varepsilon_{t}$ evolve as independent random walks $\ln \sigma_{\eta, t}^{2}=$ $\ln \sigma_{\eta, t-1}^{2}+v_{\eta, t}$ and $\ln \sigma_{\varepsilon, t}^{2}=\ln \sigma_{\varepsilon, t-1}^{2}+v_{\varepsilon, t}, \zeta_{t}=\left(\zeta_{\eta, t}, \zeta_{\varepsilon, t}\right)$ is i.i.d. $N\left(0, I_{2}\right), v_{t}=\left(v_{\eta, t}, v_{\varepsilon, t}\right)$ is i.i.d. $N\left(0, \gamma I_{2}\right)$, where $\gamma$ is a scalar parameter, and $\zeta_{t}$ and $v_{t}$ are independent. The parameter $\gamma$ is estimated recursively in real time, and the forecast of the real price of gasoline is constructed as $\hat{R}_{t+h \mid t}^{\text {gas }}=\exp \left(\hat{r}_{t+h \mid t}^{\mathrm{gas}}\right)$, where the expectation is estimated by Monte Carlo integration. 
Table A1 shows that the UC-SV model is quite accurate compared with most other models in this table, reaching reductions in the MSPE up to $22 \%$ accompanied by mostly statistically insignificant directional accuracy. One potential rationale for the UC-SV model's forecasting success at longer horizons could be time variation in the process driving gasoline prices. An alternative interpretation is that this parsimonious model can adapt to changes in the persistence of the real gasoline price process that reflect shifts in the composition of demand and supply shocks in gasoline as well as crude oil markets, each of which imparts different dynamics, even in the absence of time variation (see, for example, Kilian, 2010). We also experimented with a UC model without stochastic volatility in the permanent component. The results are uniformly less accurate than for the UC-SV model and hence are not shown.

\subsection{Forecasts Based on Spot and Futures Market Prices}

A natural question is whether information from financial markets about spot and futures prices may be used to improve the accuracy of forecasts of the real price of gasoline. For example, in the absence of a risk premium, standard arbitrage arguments imply that the gasoline futures prices should be the conditional expectation of the spot price of gasoline. This line of reasoning suggests constructing a forecast of the real retail price of gasoline as

$$
\hat{R}_{t+h \mid t}^{\mathrm{gas}}=R_{t}^{\mathrm{gas}}\left(1+f_{t}^{h}-s_{t}-E_{t}\left(\pi_{t+h}^{h}\right)\right)
$$

where $f_{t}^{h}$ is the log of the current gasoline futures price for maturity $h, s_{t}$ is the log of the corresponding spot price of gasoline and $E_{t}\left(\pi_{t+h}^{h}\right)$ is the expected inflation rate over the next $h$ periods. The latter expectation is estimated recursively and in real time using the inflation gap model proposed in Faust and Wright (2013). We follow Faust and Wright in postulating an AR(1) model for the deviation between current monthly inflation and long-run inflation expectations, as measured by the 5- to 10-year-ahead Blue Chip inflation forecast. The slope coefficient of this model is fixed at 0.429 , corresponding to the estimate obtained from the 1991:12 vintage of real-time data. Forecasts are constructed by iterating the gap model forward and adding the predicted inflation gaps to the expected trend inflation rate. ${ }^{6}$

Monthly gasoline futures price data for our evaluation period are available only up to a horizon of 6 months, limiting the applicability of this approach. Moreover, the first column of Table A2 shows that the futures-based forecast has systematically higher MSPE than the no-change forecast. The high MSPE of these forecasts does not come as a surprise given recent evidence in favor of a time-varying risk premium in the market for crude oil (see Baumeister and Kilian, 2014b). It would not be surprising if there were such a risk premium in the gasoline market as well. Although not useful from an MSPE point of view, futuresbased forecasts show some evidence of statistically significant directional accuracy at horizons 3 and 6 .

An alternative approach is the use of product spread regressions, as discussed in Baumeister et al. (2016) in the related context of oil price forecasting. This approach exploits the fact that the nominal spot prices of gasoline and crude oil are cointegrated. Under the maintained hypothesis of cointegration, current deviations of the spot price of gasoline from the spot price of crude oil would be expected to have predictive power for cumulative changes in the nominal spot price of gasoline:

$$
\Delta s_{t+h \mid t}^{h, \mathrm{gas}}=\alpha+\beta\left[s_{t}^{\mathrm{gas}}-s_{t}^{\mathrm{oil}}\right]+\varepsilon_{t+h}
$$

where $s_{t}^{\text {gas }}$ is the log of the nominal US spot price of gasoline, $s_{t}^{\text {oil }}$ is the log of the nominal spot price of

\footnotetext{
${ }^{6}$ Details of the construction of the inflation forecasts can be found in the online Appendix. Faust and Wright (2013) show that this model produces more accurate US inflation forecasts than other models used in the literature. It should be noted, however, that our results are quite robust to the use of other proxies for expected inflation.
} 
crude oil and $\Delta s_{t+h \mid t^{h, \text { gas }}}$ denotes the cumulative change in $s_{t}^{\text {gas }}$ over the next $h$ months. Analogous predictive regressions have become standard tools in financial economics (see, for example, Mark, 1995). Given recursive estimates of this relationship, one can construct the forecast of the real retail price of gasoline as

$$
\hat{R}_{t+h \mid t}^{\mathrm{gas}}=R_{t}^{\mathrm{gas}} \exp \left\{\hat{\alpha}+\hat{\beta}\left[s_{t}^{\mathrm{gas}}-s_{t}^{\mathrm{oil}}\right]-E_{t}\left(\pi_{t+h}^{h}\right)\right\}
$$

where $E_{t}\left(\pi_{t+h}^{h}\right)$ is estimated as described earlier. As shown in Baumeister et al. (2016), restricting $\alpha$ to zero may in practice reduce the MSPE of the forecast based on product spread models. Table A2 considers both versions of the model.

A potentially important question is which measure of the price of crude oil to use in the spread model. Traditionally, this question made little difference in that different measures of the price of crude oil generally moved in parallel. This is no longer true. Since 2011, the price of West Texas Intermediate (WTI) crude oil has fallen below global benchmarks such as Brent. Borenstein and Kellogg (2014) and Kilian (2016) observe that the price of gasoline in the USA in recent years has been determined by the price of crude oil imported by East Coast refineries or equivalently by the price of US exports of gasoline. This suggests that the Brent price of crude will be a better proxy in constructing the gasoline spot price spread than the price of WTI crude oil. Table A2 shows both versions of the model. It shows that there is little to choose between these specifications. Both models have higher MSPE than the no-change forecast. In both cases, imposing $\alpha=0$ in the interest of greater parsimony reduces the MSPE ratios, but without generating systematic improvements relative to the no-change forecast.

One concern in the literature has been that product spread models may have time-varying coefficients. One reason is that gasoline is jointly produced along with other refined products such that the marginal market for refined products tends to shift over time. Another reason is that the spread model does not account for a range of global and domestic disturbances to the refining market including, for example, changes in environmental regulation and refinery outages. We therefore follow Baumeister et al. (2016) in first recursively estimating the time-varying regression spread model:

$$
\Delta s_{t+h \mid t}^{h, \mathrm{gas}}=\alpha_{t}+\beta_{t}\left[s_{t}^{\mathrm{gas}}-s_{t}^{\mathrm{oil}}\right]+\varepsilon_{t+h}
$$

Given the TVP estimates, we then construct the TVP model forecast:

$$
\hat{R}_{t+h \mid t}^{\mathrm{gas}}=R_{t}^{\mathrm{gas}} \exp \left\{\hat{\alpha}_{t}+\hat{\beta}_{t}\left[s_{t}^{\mathrm{gas}}-s_{t}^{\mathrm{oil}}\right]-E_{t}\left(\pi_{t+h}^{h}\right)\right\}
$$

by Monte Carlo integration as the mean of the forecasts simulated based on 1000 Gibbs iterations conditional on the most recent data. ${ }^{7} \mathrm{We}$ also explore the effects of restricting $\alpha_{t}=0$. Table A2 shows that for most specifications allowing for time variation in the parameters results in MSPE ratios below 1 at

\footnotetext{
${ }^{7}$ In estimating this model, we postulate that $\varepsilon_{t+h} \sim$ n. i. d. $\left(0, \sigma^{2}\right)$, while the time-varying coefficients $\theta_{t}=\left[\alpha_{t}, \beta_{t}\right]^{\prime}$ evolve according to a random walk as $\theta_{t}=\theta_{t-1}+\xi_{t}$, and $\xi_{t}$ is independent Gaussian white noise with variance $Q$. This state-space model is estimated using a Gibbs sampling algorithm. The conditional posterior of $\theta_{t}$ is normal, and its mean and variance can be derived via standard Kalman filter recursions (see Kim and Nelson, 1999). Conditional on an estimate of $\theta_{t}$, the conditional posterior distribution of $\sigma^{2}$ is inverse Gamma and that of $Q$ is inverse Wishart. Our forecasts take into account that the model parameters continue to drift over the forecast horizon according to their law of motion. The first 30 observations of the initial estimation period are used as a training sample to calibrate the priors and to initialize the Kalman filter.
} 
horizon 1. Although the restricted TVP Brent spot price model in the last column shows some promise at longer horizons and produces larger MSPE reductions than any of the other spread models, overall spread models cannot be recommended. ${ }^{8}$

\subsection{Bivariate VAR Models of the Real Retail Price of Gasoline and the Real Price of Crude Oil}

Given the close relationship between gasoline and oil prices, at least in the long run, a natural extension of the univariate autoregressive forecasting models in Table A1 is a VAR model of the form $B(L) y_{t}=v$ $+u_{t}$, where $y_{t}=\left[r_{t}^{\text {oil }}, r_{t}^{\text {gas }}\right]^{\prime}$ refers to a vector including the log of the real price of crude oil and the $\log$ of the real US retail price of gasoline, $v$ denotes the intercept, $B(L)=I_{4}-B_{1} L-\ldots-B_{p} L^{p}$ denotes the autoregressive lag order polynomial, $p$ is the autoregressive lag order, $L$ is the lag operator and $u_{t}$ is a white noise innovation. As in the univariate case, forecasts $\hat{r}_{t+h \mid t}^{\text {gas }}$ are generated recursively and subsequently converted to levels. We consider forecasts both from the unrestricted least-squares estimator (denoted by VAR in the tables) and the Bayesian estimator of Giannone et al. (2015) (denoted by BVAR).

For expository purposes, Table A3 focuses on the Brent price of crude oil. Using a proxy for the global price of oil avoids the structural instability in the relationship between the US prices of crude oil and gasoline discussed in Borenstein and Kellogg (2014) and Kilian (2016). Table A3 investigates the effect of changing the lag order on the accuracy of the forecast of the level of the real price of gasoline. The baseline is the model with a fixed lag order of 12 . This model clearly outperforms the nochange forecast at horizons of 1, 3 and 6, with MSPE reductions between 5\% and 26\% and statistically significant directional accuracy as high as 0.70 . Because this model nests the AR(12) in Table A1, we conclude that past information about the real price of crude oil improves forecast accuracy.

There is no reason for this model to be optimal, however. Reducing the autoregressive lag order to 6 , results in MSPE reductions at all forecast horizons and statistically significant directional accuracy at horizons as high as 18 months. Further investigation reveals that the most accurate MSPE results are in fact obtained for the VAR(1) model. There is nothing to choose between the Bayesian and the unrestricted estimator of this model specification. Re-estimating the lag order recursively based on the AIC does not systematically improve the MSPE ratios compared with the VAR(1) model. We conclude that substantial improvements on the accuracy of real gasoline price forecasts are possible with a very simple bivariate model. ${ }^{9}$

\footnotetext{
${ }^{8}$ Building on the analysis in Baumeister et al. (2016), we also experimented with models including both the gasoline spot price spread and the heating oil spot price spread, which allow for interaction between the diesel/heating oil and gasoline retail markets. The results were similar to the gasoline spot spread model overall.

9 An obvious question is whether the MSPE reductions for the VAR(1) model are statistically significant. This question cannot be answered because none of the currently available tests of the null hypothesis of equal MSPEs is appropriate in our context. For example, the test of Diebold and Mariano (1995) does not apply in this setting. This problem is not specific to this paper. Sometimes, related studies have reported $p$-values based on the test of no predictability proposed by Clark and West (2007) for nested model comparisons with estimation uncertainty. Although all of the MSPE reductions for the VAR(1) model are statistically significant based on the latter test, we choose not to report these results because applying this test often results in statistically significant rejections, even when the MSPE ratios exceed one. For example, for the AR(12) model, the Clark and West (2007) test suggests a statistically significant reduction in the MSPE for $h=1$, notwithstanding an MSPE ratio of 1.0217. This contradiction arises because this test is biased toward rejecting the null of equal MSPEs because it tests the null of no predictability in population rather than the null of equal out-of-sample MSPEs. It also ignores the real-time nature of the data used in our forecasting exercise (see Clark and McCracken, 2013). Nor is it designed for iterated forecasts, rendering it invalid in the current setting. This criticism applies generically to similar tests of no predictability commonly used in applied work. Any such test results have to be interpreted with caution. These problems are compounded when dealing with forecasts based on model selection procedures or forecast combinations. It should be noted that the alternative test of Giacomini and White (2006), which allows for some of these complications, does not apply either in our context because it does not allow for recursive estimation. For further discussion of the problem of out-of-sample inference see Kilian (2015).
} 
Table A4 takes the lag structure as given and re-examines the sensitivity of the forecast accuracy results to the definition of the real price of crude oil. It considers four alternative definitions of the underlying nominal oil price: (i) the WTI price of crude oil; (ii) the US refiners' acquisition cost for crude oil imports with nowcasts based on the growth rate of the WTI price; (iii) the US refiners' acquisition cost for crude oil imports with nowcasts based on the growth rate of the Brent price of oil; and (iv) the Brent price of crude oil. Specifications (ii) and (iii) have been used in the related literature on modeling the global market for crude oil. Table A4 confirms that the choice of the oil price series matters. As expected, the WTI specification yields the highest MSPE ratios, whereas the Brent specification yields the lowest MSPE ratios. This result is consistent with the economic arguments in Borenstein and Kel$\log$ (2014) and Kilian (2016) that the US price of gasoline is determined by the price of crude oil in global markets rather than the WTI price. At some horizons, the reduction in the MSPE ratio can be as high as 0.08 . Thus, for the remainder of the paper, we focus on the Brent price only.

Table A5 returns to the question of whether the real prices of gasoline and crude oil should be modeled in log-levels or not. Because oil and gasoline prices move together in the long run, as illustrated in Figure A2, a VAR model under the unit root null hypothesis must treat them as cointegrated. In this case, a VAR model for variables In percent changes would be invalid. In contrast, the VAR model in log-levels remains valid, but there is a possible efficiency gain from imposing cointegration in estimating the VAR model. The implied vector error correction (VEC) representation of this model can equivalently be expressed in triangular form as a VAR model for $y_{t}=\left[\Delta r_{t}^{\text {gas }}, r_{t}^{\text {gas }}-r_{t}^{\text {oil }}\right]^{\prime}$. This model is labeled VEC or BVEC in Table A5, depending on whether the model is estimated by unrestricted least squares or by Bayesian methods.

Whether imposing cointegration reduces the MSPE of the out-of-sample forecasts is an empirical question (see, for example, Christoffersen and Diebold, 1998). The first two columns of the table provide the earlier VAR(1) and BVAR(1) results as a benchmark. Fitting a VEC(1) or BVEC(1) model generates no reductions in the MSPE at any horizon. Allowing for six lags improves the MSPE ratios at horizons up to 9 months. Further improvements are obtained with 12 lags, which turns out to be the most accurate VEC specification overall. The use of Bayesian estimation methods makes little difference for this model. Even the most accurate VEC model is not as accurate as the VAR(1) model in levels, however. Thus the possibility of cointegration may for all practical purposes be ignored in forecasting the real price of gasoline.

\subsection{Models of the US Retail Gasoline Market}

Rather than linking the monthly real retail price of gasoline to the price of crude oil in global markets, another strategy is to model its connections to the state of the domestic economy. A common monthly measure of US real activity is the Chicago Fed National Activity Index (CFNAI). ${ }^{10}$ Vintages for this index are available from January 2001 onwards; earlier vintages are constructed as pseudo real-time data taking account of the 1-month delay in the availability of the index. Nowcasts are constructed using exponential smoothing with weight $a=0.95$. $^{11}$

\footnotetext{
10 The CFNAI is a weighted average of 85 monthly indicators of US real economic activity. These indicators are drawn from four broad categories of data: production and income; employment, unemployment, and hours; personal consumption and housing; and sales, orders and inventories. The index corresponds to the leading common factor contained in the growth rates of these 85 series and has been shown to be a useful gauge on current and future economic activity and inflation in the USA. As is standard, we rely on the smoothed version of the CFNAI based on a one-sided moving average filter. For further details see https:// www.chicagofed.org/publications/cfnai/index.

11 The same smoothing parameter value was also used by Faust and Wright (2013) for the unemployment rate, which is one of the components of the CFNAI index. As is typical in exponential smoothing problems, the precise choice of smoothing parameter makes little difference.
} 
A natural conjecture is that the demand for gasoline and hence the real price of gasoline responds to changes in the US business cycle. One way of capturing this intuition is to construct a parsimonious factor forecasting model:

$$
\Delta r_{t+h \mid t}^{h, \text { gas }}=\alpha+\beta c f n a i_{t}+\varepsilon_{t+h}
$$

where $\Delta r_{t+h \mid t}^{h \text {,gas }}$ denotes the cumulative percent change in the real price of gasoline expressed as a fraction such that $\hat{R}_{t+h \mid t}^{\text {gas }}=\exp \left(r_{t}^{\text {gas }}+\Delta \hat{r}_{t+h \mid t}^{h \text {,gas }}\right)$, and cfnai ${ }_{t}$ the common factor. Table A6 shows that this model does not improve on the MSPE of the no-change forecast at any horizon and lacks directional accuracy at all horizons. An alternative strategy is to construct a factor-augmented VAR (FAVAR) model including the real retail price of gasoline and the CFNAI. Among all such models the specification involving 12 lags performed best. Even this specification offers little improvement, however. Although it has some non-negligible statistically significant directional accuracy at horizons 1-9, as shown in Table A6, it tends to have higher MSPE than the no-change forecast and cannot be recommended. The same is true for Bayesian estimates of the FAVAR model, denoted by BFAVAR in Table A6.

This result is not entirely surprising upon reflection, given the fall in US gasoline consumption in recent years that was not related to the US business cycle so much, but to rising gasoline prices. This fact suggests specifying instead a bivariate VAR model with intercept for the log-level of the real price of gasoline and the log of US real gasoline consumption. The results shown in Table A6 are based on a model specification involving the log-difference of the real gasoline consumption rather than the loglevel. Imposing this restriction tends to reduce the MSPE. As before, $\hat{R}_{t+h \mid t}^{\text {gas }}=\exp \left(\hat{r}_{t+h \mid 1}^{\text {gas }}\right)$. Table A6 shows that the VAR(12) and BVAR(12) specification in some dimensions improve on the corresponding FAVAR(12) and BFAVAR(12) models, but not by much. Clearly, neither approach can be recommended. This result is robust to changes in the lag order. Table A6 shows two representative examples involving six autoregressive lags and one autoregressive lag.

\subsection{Joint VAR Models of the US Retail Gasoline Market and the Global Market for Crude Oil}

In Section 3.2 we showed that including the real price of oil in the same VAR model as the real retail price of gasoline greatly enhances the forecast accuracy. A natural question therefore is whether combining forecasting models of the US retail gasoline market with forecasting models of the global price of crude oil may improve the accuracy of gasoline price forecasts further. Such an improvement is by no means self-evident, given the large dimensionality of models that combine both oil and gasoline market blocks.

A natural benchmark is the VAR(12) forecasting model for the real price of oil first proposed in Baumeister and Kilian (2012). This VAR model may be viewed as the reduced-form representation of the structural global oil market model developed in Kilian and Murphy (2014). It includes the percent change in global crude oil production, a measure of global real economic activity, the log of the real US refiners' acquisition cost for crude oil imports as a proxy for the global price of oil and a proxy for the change in global crude oil inventories. ${ }^{12}$ For the purposes of the current paper, we augment the forecasting model of Baumeister and Kilian (2012) by a gasoline market block consisting of the logdifference of US real gasoline consumption and the log-level of the real US retail price of gasoline, resulting in a model with six variables. ${ }^{13}$ We follow the oil price forecasting literature in estimating

\footnotetext{
12 The inventory data are constructed by multiplying US crude oil inventories by the ratio of OECD petroleum inventories to US petroleum inventories. Petroleum inventories are defined to include both stocks of crude oil and stocks of refined products. The global real activity index is constructed from data on global dry cargo ocean shipping freight rates as described in Kilian (2009).

${ }^{13}$ For the large-scale VAR models it can be shown that a specification in the log-level of real gasoline consumption is even more accurate by a few percentage points, but we report the results for the log-difference to maintain consistency with the earlier bivariate analysis.
} 
the unrestricted VAR model with 12 autoregressive lags by the method of least squares or by Bayesian methods. It can be shown that this lag order choice not only works well in forecasting the real price of oil, but also generates more accurate real gasoline price forecasts than shorter or longer lag structures. As before, forecasts $\hat{r}_{t+h \mid t}^{\text {gas }}$ of the log of the real price of oil are constructed iteratively from the estimated VAR model conditional on the most recent data and converted to levels, resulting in the forecast $\hat{R}_{t+h \mid t}^{\text {gas }}=\exp \left(\hat{r}_{t+h \mid t}^{\text {gas }}\right)$.

The first two columns of Table A7 show that this large-scale model is surprisingly accurate at short horizons with MSPE ratios as low as 0.73 and statistically significant directional accuracy as high as 0.69. Not surprisingly, given the short estimation samples, the use of Bayesian estimation methods further improves the forecast accuracy of this high-dimensional model. The BVAR(12) model produces MSPE reductions between 3\% and 28\% at horizons up to 9 months, accompanied by mostly statistically significant directional accuracy as high as 0.72 . Thus, at short horizons, this model is more accurate than the VAR(1) model for the real prices of gasoline and Brent crude oil in Table A3. At longer horizons, this ranking is reversed, given the greater parsimony of the VAR(1) model. The next two columns focus on a simplified version of the first model, in which the second block only includes the log of the real price of gasoline, but excludes the log of real gasoline consumption. This model is marginally less accurate than the six-variable model at very short horizons, but marginally more accurate at horizons of more than 3 months. Overall, the results are quite similar.

The remainder of Table A7 examines the robustness of these results based on another joint VAR model of the gasoline and crude oil markets proposed in Kilian (2010). The reduced-form representation of the latter model consists of the same two blocks as before, except that the oil inventory data are excluded from the first block. The next two columns of Table A7 show that similar results are obtained with this five-variable model than with the original specification. Likewise, after dropping real gasoline consumption from this model, as shown in the last two columns, the resulting four-variable model produces forecasts of the real gasoline price that are about as accurate as those from the earlier fivevariable model including oil inventories.

We conclude that, at short forecast horizons, high-dimensional joint forecasting models of the real price of oil and the real retail price of gasoline outperform in real time not only the no-change forecast but also the bivariate VAR(1) model forecast, based on real Brent oil and gasoline prices. This result is quite striking. It demonstrates that parsimony does not always win out in forecasting.

\section{SENSITIVITY ANALYSIS AND REFINEMENTS}

This section examines the robustness of our results along four dimensions. We first assess the importance of explicitly modeling seasonality in the real price of gasoline. We then examine the robustness of the recursive MSPE rankings over time, and we explore the benefits of pooling the most successful gasoline price forecasts. Finally, we extend the analysis to quarterly gasoline price forecasts.

\subsection{How Important Is Seasonality in Gasoline Prices?}

It is well known that there is pronounced seasonality in the production of gasoline. It is less clear how important seasonality is in the monthly retail price of gasoline. Figure A1 does not suggest a strong seasonal pattern. Nevertheless, formal statistical tests for deterministic seasonal effects in the growth rate of the monthly real price of gasoline conducted on the full sample using fully revised data indicate statistically significant seasonal variation during some months of the year. Our analysis so far has not explicitly incorporated this seasonal variation. It can be shown that including monthly seasonal dummies in the forecasting models does not systematically improve its real-time forecast accuracy and in some cases may worsen it, indicating that the reduction in forecast bias from modeling seasonal 

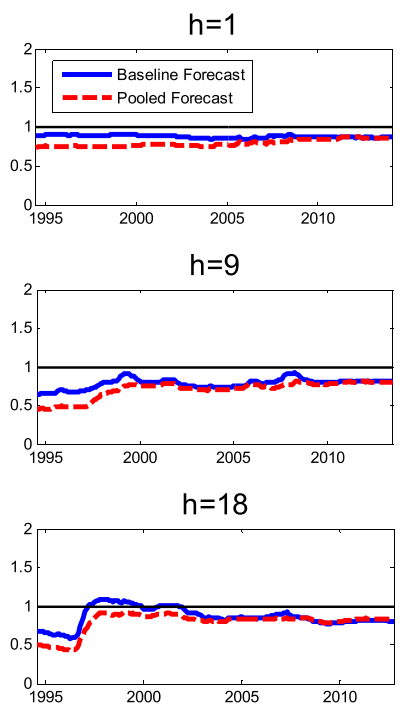

$h=3$
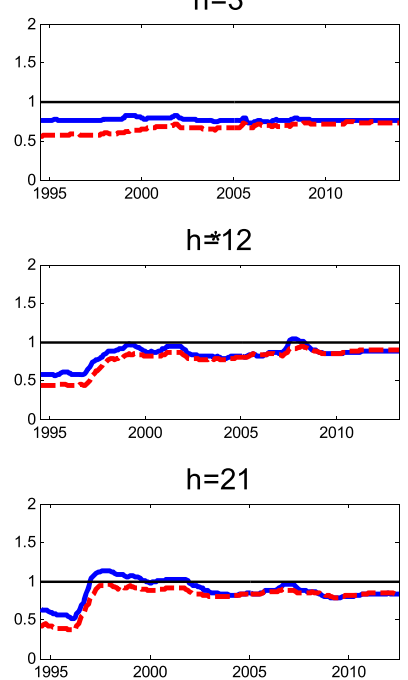

$\mathrm{h}=6$
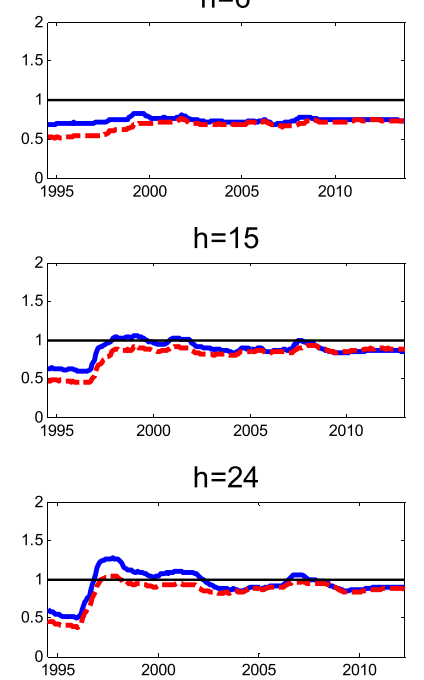

NOTES: The plot shows the evolution of the recursive MSPE ratio over time for the forecast evaluation period since the beginning of the evaluation period. The first 30 observations in each subplot have been discarded to allow the MSPE estimates to stabilize. A ratio below 1 indicates an improvement relative to the no-change forecast. The baseline forecast is from the VAR(1) model for real Brent and real retail gasoline prices in Table A3. The pooled forecast assign equal weight to the VAR(1) Brent model, the VEC(12) Brent model, the exponential smoothing forecast, the UC-SV model, and the Kilian-Murphy BVAR(12) specification with the real gasoline price added.

Figure 1. Evolution of the real-time recursive MSPE ratio relative to the no-change forecast by horizon. The plot shows the evolution of the recursive MSPE ratio over time for the forecast evaluation period since the beginning of the evaluation period. The first 30 observations in each subplot have been discarded to allow the MSPE estimates to stabilize. A ratio below 1 indicates an improvement relative to the no-change forecast. The baseline forecast is from the VAR(1) model for real Brent and real retail gasoline prices in Table A3. The pooled forecast assigns equal weight to the VAR(1) Brent model, the VEC(12) Brent model, the exponential smoothing forecast, the UC-SV model and the Kilian-Murphy BVAR(12) specification, with the real gasoline price added. [Colour figure can be viewed at wileyonlinelibrary.com]

variation is outweighed by the additional variance caused by having to estimate these additional parameters. Thus seasonality may be ignored for the purpose of generating out-of-sample gasoline price forecasts.

\subsection{How Robust Are the MSPE Reductions Over Time?}

The analysis so far has focused on the recursive MSPE ratio at the end of the evaluation sample. This ratio is a measure of the overall predictive power of the forecasting method. Of equal importance from the point of view of an applied user is how robust these gains in forecast accuracy have been over time. This question may be assessed by plotting the recursive MSPE ratio, as it evolves during the evaluation period. In Figure 1 we address this question for the VAR(1) model of the real prices of gasoline and Brent crude oil, which proved most accurate overall in Section 3. The forecast from this model is referred as the baseline forecast in Figure 1. The last observation shown for the recursive MSPE ratio in each subplot corresponds to the entry for this horizon shown in the earlier tables. ${ }^{14}$

\footnotetext{
${ }^{14}$ It should be noted at this point that our concern here is with demonstrating that the VAR(1) model has had lower MSPE than the no-change forecast consistently over time. We are not concerned with the question of whether there is statistically significant variation over time in the MSPE ratios. Indeed, that question is irrelevant for our analysis. Moreover, tests of the latter hypothesis, as discussed in Giacomini and Rossi (2010), rely on the framework of Giacomini and White (2006), which only applies to forecasts based on rolling windows. Such tests are not valid in our setting.
} 
Figure 1 demonstrates that the accuracy of the VAR(1) forecasting model has been remarkably stable over time. At horizons up to 9 months, the recursive MSPE ratio has been below 1 for every month between the beginning of the evaluation period and March 2014. At horizons of 12 and 15 months, it has reduced the MSPE most of the time; even at horizons of 18 and 21 months it has remained superior to the no-change forecast more often than not; only at the horizon of 24 months has its relative accuracy been somewhat erratic. Figure 1 establishes the robustness of the accuracy of the VAR(1) baseline forecast of the real price of gasoline price at horizons at least up to 15 months. This finding is by no means a foregone conclusion. The VAR(6) model in Table A3, for example, performs rather poorly in the first two-thirds of the evaluation sample, especially at short horizons. Likewise, the accuracy of the large-scale BVAR(12) models in Table A7 and of the bivariate VEC(12) model in Table A5 is not as stable at horizon 1 as the bivariate VAR(1) model. We conclude that the VAR(1) forecasting model based on real Brent and real retail gasoline prices is preferred over the other models, not only in terms of its overall accuracy but also its robustness.

\subsection{Are There Benefits from Forecast Pooling?}

Forecast combinations (also known as pooled forecasts) have a long tradition in macroeconomic forecasting (see, for example, Timmermann, 2006). They have also been shown to be helpful in

Table I. Real-time forecast accuracy of pooled real gasoline price forecasts: Evaluation period 1992:1-2014.3

\begin{tabular}{|c|c|c|}
\hline \multirow[b]{2}{*}{$\begin{array}{l}\text { Monthly } \\
\text { horizon }\end{array}$} & \multicolumn{2}{|c|}{$\begin{array}{l}\text { Equal-weighted } \\
\text { combination of five } \\
\text { forecasting models }\end{array}$} \\
\hline & $\begin{array}{l}\text { MSPE } \\
\text { ratio }\end{array}$ & $\begin{array}{c}\text { Success } \\
\text { ratio }\end{array}$ \\
\hline 1 & 0.856 & $0.588^{*}$ \\
\hline 2 & 0.768 & $0.613 *$ \\
\hline 3 & 0.735 & $0.642 *$ \\
\hline 4 & 0.733 & $0.671^{*}$ \\
\hline 5 & 0.733 & $0.662 *$ \\
\hline 6 & 0.736 & $0.649 *$ \\
\hline 7 & 0.742 & $0.667 *$ \\
\hline 8 & 0.763 & $0.635^{*}$ \\
\hline 9 & 0.800 & $0.606^{*}$ \\
\hline 10 & 0.846 & 0.574 \\
\hline 11 & 0.800 & 0.572 \\
\hline 12 & 0.895 & 0.547 \\
\hline 13 & 0.897 & 0.541 \\
\hline 14 & 0.891 & 0.534 \\
\hline 15 & 0.879 & 0.561 \\
\hline 16 & 0.859 & $0.599 *$ \\
\hline 17 & 0.839 & $\mathbf{0 . 5 9 4} * *$ \\
\hline 18 & 0.826 & $0.596^{* *}$ \\
\hline 19 & 0.824 & $0.594 * *$ \\
\hline 20 & 0.825 & $0.613^{*}$ \\
\hline 21 & 0.838 & 0.583 \\
\hline 22 & 0.857 & 0.553 \\
\hline 23 & 0.855 & 0.551 \\
\hline 24 & 0.872 & 0.541 \\
\hline
\end{tabular}

Note: The pooled forecast is an equal-weighted average of forecasts from: (i) the Brent VAR(1) model; (ii) the Brent VEC(12) model, (iii) the UC-SV model forecast, (iv) the exponential smoothing forecast and (v) the Kilian-Murphy BVAR(12) model specification with the real gasoline price added. All forecasts are generated recursively from data subject to real-time data constraints. Bold type indicates improvements relative to the no-change forecast. A single asterisk denotes significance at the 5\% level and double asterisks denote on significance at the 10\% level based on Pesaran and Timmermann's (2009) test for the null hypothesis of no directional accuracy. The statistical significance of the MSPE reductions cannot be assessed because none of the currently available tests of equal predictive accuracy applies in this setting. 
forecasting energy prices. For example, Baumeister and Kilian (2014a) and Baumeister et al. (2014) establish that an equal-weighted combination of suitably selected oil price forecasting models is systematically more accurate than any individual forecast, including the no-change forecast. It also is more accurate than forecast combinations based on recursive or rolling inverse MSPE weights. It therefore makes sense to explore the benefits of pooling in our context. Rather than pooling all gasoline price forecasts, we illustrate the benefits of pooling by focusing on the five most promising forecasting approaches considered so far, which include the exponential smoothing forecast and the UC-SV forecast in Table A1, the Brent VAR(1) model in Table A3, the Brent VEC(12) model in Table A5 and the Kilian-Murphy large-scale BVAR(12) specification with the real price of gasoline added in Table A7. Table 1 shows that combining these models with equal weights of $1 / 5$ is superior overall to relying on the most accurate individual model. The pooled forecast improves on the no-change forecast at all horizons between 1 and 24 months, with MSPE ratios as low as 0.73 and success ratios as high as 0.67. It also improves substantially on the MSPE of the Brent VAR(1) model in Table A3 at some horizons and is only marginally less accurate than the VAR(1) model at the other horizons.

In addition, the accuracy of the pooled forecast is more stable over time than that of the VAR(1) model forecast. Figure 1 shows that the recursive MSPE of the pooled forecast is below that of the no-change forecast in every month of the 20-year evaluation period at all horizons except at horizon 24 and, even in that case, it dominates the no-change forecast at all but a few months of the evaluation period. Pooling forecasts systematically reduce the recursive MSPE ratio relative to the baseline VAR (1) model forecast at all horizons. We conclude that pooling the five forecasting models in question with equal weights is the preferred forecasting approach in practice. ${ }^{15}$

\subsection{Extensions to Quarterly Forecasts of the Real Price of Gasoline}

It is straightforward to derive quarterly forecasts by averaging the monthly forecasts by quarter. This approach has been shown to be considerably more accurate than relying on quarterly data in the construction of the quarterly forecasts when forecasting the price of oil (see Baumeister and Kilian, 2014a). Quarterly forecasts are not only required to compare our forecasting methods to existing quarterly forecasts prepared by the EIA in Section 5, but are of independent interest to macroeconomists. Macroeconomic models are typically specified at quarterly frequency, necessitating the construction of quarterly gasoline price forecasts. The analysis of quarterly forecasts also provides an important robustness check, because by construction the accuracy of quarterly forecasts may not be inferred from that of the monthly forecasts we reported earlier (see Baumeister and Kilian, 2014a). Figure 2 shows that the pattern of the recursive MSPE ratios of the quarterly pooled forecasts is similar to that of the monthly pooled forecasts in Figure 1. The improvements in accuracy are even higher than for the monthly forecasts. The overall recursive MSPE reductions range from $15 \%$ to $31 \%$, with success ratios as high as 0.71 and statistically significant directional accuracy up to 6 quarters. ${ }^{16}$

\footnotetext{
15 Additional reductions in the overall recursive MSPE are possible, when selecting the most accurate forecast combination for each horizon, as proposed in Baumeister and Kilian (2015). Further analysis, however, showed that the accuracy of this alternative pooled forecast is less robust over time, especially at horizons 1 and 24 , than the original pooled forecast.

16 The benchmark in Fig. 2 is the same monthly no-change forecast as in the earlier analysis. This no-change forecast at short horizons is considerably more accurate than the quarterly no-change forecast (see Baumeister and Kilian, 2014a). 

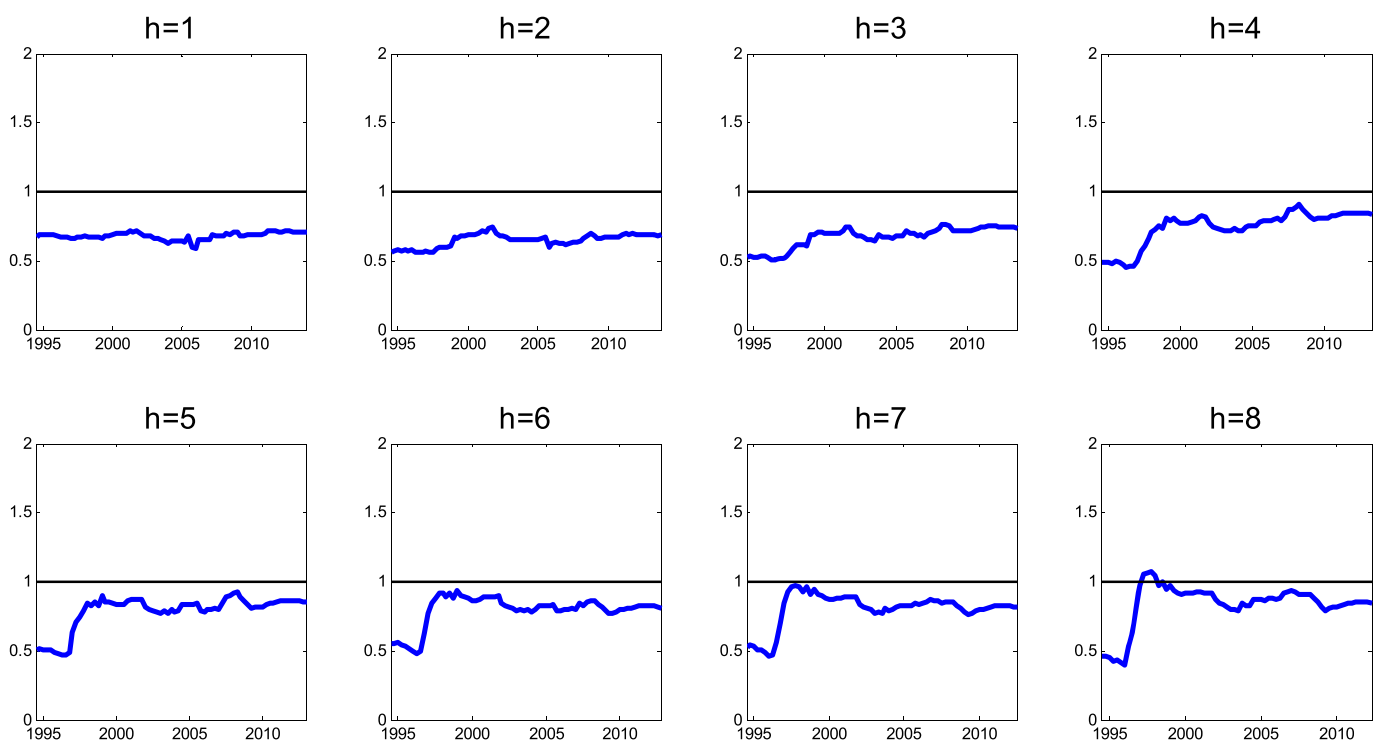

NOTES: The pooled forecast is based on an equally weighted average of five individual forecasts. The results are constructed as in Figure 1 except that the monthly forecasts are averaged by quarter, for quarters $h \in\{1, \ldots, 8\}$, as proposed in Baumeister and Kilian (2014a).

Figure 2. Evolution of the real-time recursive MSPE ratio of the quarterly pooled forecast relative to the no-change forecast by horizon. The pooled forecast is based on an equally weighted average of five individual forecasts. The results are constructed as in Figure 1, except that the monthly forecasts are averaged by quarter, for quarters $h \in\{1, \ldots, 8\}$, as proposed in Baumeister and Kilian (2014a). [Colour figure can be viewed at wileyonlinelibrary.com]

\section{A COMPARISON OF ECONOMETRIC GASOLINE PRICE FORECASTS AND OTHER FORECASTS}

A different perspective on the accuracy of pooled real-time forecasts may be obtained by comparing them to the short-term nominal gasoline price forecasts published by the EIA. The data source for the latter forecasts is the EIA's Short-Term Energy Outlook. These forecasts are intended to help businesses, households and governments in their decision making. A natural question is how accurate these forecasts are and whether they may be improved upon by using the pooled forecast proposed in this paper. We construct quarterly nominal pooled forecasts by averaging the monthly pooled forecasts of the real price by quarter, as in Figure 2, and inflating these forecasts based on the method of Faust and Wright (2013). The benchmark is the monthly nominal no-change forecast. Table 2 shows that the EIA forecasts are quite accurate at horizons up to four quarters as measured by the MSPE, which is in sharp contrast to the EIA's much less accurate oil price forecasts (see Baumeister et al. 2014). Nevertheless, the pooled forecast is even more accurate and hence preferable. As far as directional accuracy is concerned, both approaches yield improvements on the no-change forecast, with no clear winner.

It is also of interest to compare the pooled forecast with the average expected nominal gasoline price implied by the Michigan Survey of Consumers. ${ }^{17}$ The evaluation sample is restricted by the availability of the survey data. Table 2 shows that the MSPE of the 12-month-ahead survey forecast is larger than

\footnotetext{
17 Unlike Anderson et al. (2011), we do not evaluate the implied real gasoline price forecast but the nominal price forecast. Our survey forecast is constructed by averaging the expected change in the nominal gasoline price across households and adding it to the current nominal price of gasoline.
} 
Table II. Real-time forecast accuracy of nominal retail gasoline price forecasts

\begin{tabular}{|c|c|c|c|c|}
\hline \multirow[b]{2}{*}{ Horizon } & \multicolumn{2}{|c|}{$\begin{array}{l}\text { Quarterly forecasts } \\
\text { Evaluated on 1992:I-2014:I }\end{array}$} & \multicolumn{2}{|c|}{$\begin{array}{l}\text { Monthly forecasts } \\
\text { Evaluated on 2006:3-2014:3 }\end{array}$} \\
\hline & EIA & Pooled & $\begin{array}{l}\text { Michigan } \\
\text { Survey }\end{array}$ & Pooled \\
\hline \multicolumn{5}{|c|}{ MSPE ratios } \\
\hline 1 quarter & $0.789 *$ & 0.717 & - & - \\
\hline 2 quarters & $0.838^{*}$ & 0.695 & - & - \\
\hline 3 quarters & $0.840 *$ & 0.736 & - & - \\
\hline 4 quarters & $0.895 * *$ & 0.816 & - & - \\
\hline 12 months & - & - & 1.051 & 0.904 \\
\hline \multicolumn{5}{|c|}{ Success ratios } \\
\hline 1 quarter & $0.652 *$ & $0.742 *$ & - & - \\
\hline 2 quarters & $0.693 *$ & $0.671 *$ & - & - \\
\hline 3 quarters & $0.621 *$ & $0.586 * *$ & - & - \\
\hline 4 quarters & $0.640 *$ & $0.640 * *$ & - & - \\
\hline 12 months & - & - & 0.651 & $0.674 *$ \\
\hline
\end{tabular}

Note: The EIA real-time forecasts were compiled from the Short-Term Energy Outlook. The average expected change in the nominal price of gasoline in the Michigan Survey of Consumers was obtained from Soren Anderson. The pooled forecast is based on the specification underlying Table 1 . The monthly pooled forecasts are averaged by quarter, if required, and are inflated using real-time inflation forecasts constructed as in Faust and Wright (2013). The benchmark is the monthly no-change forecast for the nominal price of gasoline. A single asterisk denotes significance at the 5\% level and double asterisks denote on significance at the $10 \%$ level based on Pesaran and Timmermann's (2009) test for the null hypothesis of no directional accuracy and, in the case of the survey forecasts only, the Diebold and Mariano's (1995) test of equal predictive accuracy. The statistical significance of the other MSPE reductions cannot be assessed because none of the currently available tests of equal predictive accuracy applies in this setting.

that of the no-change forecast and that the directional accuracy of the survey forecast is not statistically significant. The pooled forecast has a lower MSPE and higher directional accuracy than the monthly survey forecast. One interpretation of this evidence is that the simple rules of thumb used by US households to form gasoline price expectations are suboptimal.

Table III. Selected real-time forecast paths for the US retail price of gasoline in cents/gallon: How predictable was the decline in gasoline prices after June 2014?

\begin{tabular}{|c|c|c|c|c|c|c|c|c|c|c|c|c|}
\hline \multirow{2}{*}{\multicolumn{2}{|c|}{$\begin{array}{l}\text { Real-time gasoline price } \\
\text { forecasts as of June } 2014\end{array}$}} & \multicolumn{8}{|c|}{2014} & \multicolumn{3}{|c|}{2015} \\
\hline & & $\begin{array}{r}\text { May } \\
376\end{array}$ & $\begin{array}{l}\text { Jun } \\
377\end{array}$ & $\begin{array}{l}\text { Jul } \\
373\end{array}$ & Aug & Sep & Oct & Nov & Dec & $\begin{array}{l}\text { Jan } \\
353\end{array}$ & $\begin{array}{l}\text { Feb } \\
354\end{array}$ & $\begin{array}{r}\text { March } \\
355\end{array}$ \\
\hline Real & $\begin{array}{l}\text { Pooled } \\
\text { KM-BVAR(12) } \\
\text { EIA } \\
\text { Actual }\end{array}$ & $\begin{array}{l}376 \\
376 \\
376 \\
376\end{array}$ & $\begin{array}{l}377 \\
377 \\
373 \\
375\end{array}$ & $\begin{array}{l}373 \\
376 \\
367 \\
368\end{array}$ & $\begin{array}{l}370 \\
370 \\
361 \\
352\end{array}$ & $\begin{array}{l}364 \\
359 \\
359 \\
344\end{array}$ & $\begin{array}{l}359 \\
346 \\
347 \\
321\end{array}$ & $\begin{array}{l}356 \\
334 \\
337 \\
292\end{array}$ & $\begin{array}{l}354 \\
326 \\
327 \\
259\end{array}$ & $\begin{array}{l}353 \\
324 \\
327 \\
214\end{array}$ & $\begin{array}{l}354 \\
326 \\
332 \\
227\end{array}$ & $\begin{array}{l}355 \\
328 \\
341 \\
249\end{array}$ \\
\hline Nominal & $\begin{array}{l}\text { Pooled } \\
\text { KM-BVAR(12) } \\
\text { EIA } \\
\text { Actual }\end{array}$ & $\begin{array}{l}374 \\
374 \\
375 \\
375\end{array}$ & $\begin{array}{l}\mathbf{3 7 7} \\
\mathbf{3 7 7} \\
\mathbf{3 7 3} \\
375\end{array}$ & $\begin{array}{l}374 \\
377 \\
368 \\
369\end{array}$ & $\begin{array}{l}371 \\
372 \\
363 \\
354\end{array}$ & $\begin{array}{l}367 \\
362 \\
361 \\
346\end{array}$ & $\begin{array}{l}362 \\
349 \\
350 \\
324\end{array}$ & $\begin{array}{l}360 \\
337 \\
341 \\
295\end{array}$ & $\begin{array}{l}358 \\
330 \\
331 \\
262\end{array}$ & $\begin{array}{l}358 \\
329 \\
332 \\
217\end{array}$ & $\begin{array}{l}359 \\
331 \\
337 \\
231\end{array}$ & $\begin{array}{l}361 \\
335 \\
347 \\
254\end{array}$ \\
\hline
\end{tabular}

Note: Nowcasts are shown in bold; forecasts in italics. By construction, the nominal and the real price coincide in the last nowcast period. The pooled forecast is an equal-weighted average of five individual real-time forecasts, as reported in Table 1. The KMBVAR(12) model is augmented with the real retail price of gasoline. These forecasts are converted to nominal terms using realtime inflation forecasts constructed analogously to Faust and Wright (2013). The real price of gasoline is expressed in June 2014 dollars. 


\section{HOW PREDICTABLE WAS THE DECLINE IN GASOLINE PRICES IN LATE 2014?}

There has been much public discussion about the rapid decline in the US retail price of gasoline since June 2014. The question of whether this decline was predictable is of interest to economists because it helps us determine the extent to which this decline must be attributed to economic shocks occurring after June 2014. If the decline were entirely predictable as of June 2014, for example, there would be no point in searching for additional economic shocks after June 2014 to which to attribute this decline. Table 3 shows several real and nominal real-time gasoline price forecasts generated as of June 2014. It shows that about $39 \%$ of the price decline between June and December was actually predicted by the EIA in real time. Much the same result would have been obtained by forecasting gasoline prices in real time based on the Kilian-Murphy BVAR(12) model augmented by US retail gasoline prices. In contrast, the pooled forecast, which overall proved clearly more accurate than the EIA forecast in Table 2, only predicted about $16 \%$ of this particular decline. This result suggests that the insurance against forecast errors provided by pooling forecasts, although effective on average, during some specific episodes may come at a high cost.

In fact, the only model contained in the forecast combination to come close to the EIA forecast is the KM-BVAR(12) model. One reason for the favorable performance of this forecasting framework is that this model involves explicit forecasts of global real activity and that it anticipated falling demand for oil in the second half of 2014, consistent with an economic slowdown in Europe and Asia. In addition, the inclusion of oil inventories and global oil production can be shown to improve the accuracy of the VAR model forecast substantially. As discussed in Baumeister and Kilian (2015), VAR forecasting models motivated by structural oil market models tend to work well during times when economic fundamentals show persistent variation, but less well at other times. This fact suggests that it may make sense to use time-varying weights in the forecast combination. For example, one may choose to depart from the baseline pooled gasoline price forecast in favor of the VAR forecast, when the VAR forecast starts tracking the realizations of the gasoline price much more accurately than the pooled forecast, and one may revert to the baseline pooled forecast when it no longer does.

\section{CONCLUDING REMARKS}

The price of gasoline is arguably the most closely watched retail price in the economy. The change in the gasoline price in the past has been considered essentially unforecastable based on publicly available information. Our findings challenge this conventional wisdom. We compared a wide range of alternative approaches to generating short-term forecasts of the real US retail price of gasoline at horizons up to 2 years, drawing on insights from the related literature on forecasting the real price of crude oil. Our analysis was conducted in real time, taking account of delays in the availability of some data and of subsequent revisions when data finally become available. We identified five forecasting approaches that generate systematic real-time improvements in accuracy compared with the no-change forecast. An equal-weighted average of these five forecasts yields substantial reductions in the MSPE at all horizons up to 24 months and significant directional accuracy. The accuracy of this pooled forecast is remarkably stable over an evaluation period covering the last 20 years. We also discussed extensions of our analysis to forecasting quarterly aggregates of the real price of gasoline as well as forecasting nominal gasoline prices. In the latter case, the accuracy gains are even larger, with MSPE reductions as high as $31 \%$ and directional accuracy as high as $74 \%$. Finally, we compared our forecasts to expert and survey forecasts, and we provided evidence that as much as $39 \%$ of the decline in US retail gasoline prices in late 2014 was predictable as of June 2014.

Our analysis provides a set of tools for forecasting gasoline prices with a wide range of applications in macroeconomics, environmental economics, urban economics and public finance. Our results are of particular interest to central bankers, regulators, industry analysts, tax authorities and perhaps, most 
importantly, consumers. There are a number of interesting extensions to be considered in future work. For example, one could extend the analysis to forecast gasoline prices at the state or regional level. One could also extend the set of predictors to include gasoline stocks, gasoline production and data on operable refining capacity, planned outages and capacity utilization (also see EIA, 2014). Another question of interest would be whether pre-testing for seasonal effects and specifying a more parsimonious model of seasonal variation in gasoline prices can improve forecast accuracy. In addition, an investigation into the usefulness of gasoline price forecasts in improving inflation forecasts would be of interest to macroeconomists (see, for example, Hendry and Hubrich, 2011). Moreover, Edelstein and Kilian (2009) document that gasoline price shocks are associated with significant reductions in spending as well as in consumer confidence, suggesting that gasoline price forecasts may also help improve forecasts of US economic growth.

\section{ACKNOWLEDGEMENTS}

The work of Lutz Kilian was supported by grant \#F034514 from the US Energy Information Administration. We thank Soren Anderson for providing access to the survey data on gasoline price expectations and Ryan Kellogg for helpful discussions. Christopher Hau provided excellent research assistance. We have also benefitted from comments by three anonymous referees and the Editor.

\section{REFERENCES}

Allcott H, Wozny N. 2014. Gasoline prices, fuel economy, and the energy paradox. Review of Economics and Statistics 96: 779-795.

Alquist R, Kilian L, Vigfusson RJ. 2013. Forecasting the price of oil. In Handbook of Economic Forecasting, Vol. 2, Elliott G, Timmermann A (eds.). North-Holland: Amsterdam; 427-507.

Anderson ST, Kellogg R, Sallee JM, Curtin RT. 2011. Forecasting gasoline prices using consumer surveys. American Economic Review: Papers and Proceedings 101: 110-114.

Anderson ST, Kellogg R, Sallee JM. 2013. What do consumers believe about future gasoline prices? Journal of Environmental Economics and Management 66: 383-403.

Bachmeier LJ, Griffin JM. 2003. New evidence on asymmetric gasoline price responses. Review of Economics and Statistics 85: 772-776.

Bastianin A, Galeotti M, Manera M. 2014. Forecasting the oil-gasoline price relationship: do asymmetries help? Energy Economics 46(Suppl. 1): S44-S56.

Baumeister C, Kilian L. 2012. Real-time forecasts of the real price of oil. Journal of Business and Economic Statistics 30: 326-336.

Baumeister C, Kilian L. 2014a. What central bankers need to know about forecasting oil prices. International Economic Review 55: 869-889.

Baumeister C, Kilian L. 2014b. A general approach to recovering market expectations from futures prices with an application to crude oil. Working paper, University of Michigan.

Baumeister C, Kilian L. 2015. Forecasting the real price of oil in a changing world: a forecast combination approach. Journal of Business and Economic Statistics 33: 338-351.

Baumeister C, Kilian L, Lee TK. 2014. Are there gains from pooling real-time oil price forecasts? Energy Economics 46: S33-S43.

Baumeister C, Kilian L, Zhou X. 2016. Are product spreads useful for forecasting oil prices? An empirical evaluation of the Verleger hypothesis. Macroeconomic Dynamics (forthcoming).

Baumeister C, Guérin P, Kilian L. 2015. Do high-frequency financial data help forecast oil prices? The MIDAS touch at work. International Journal of Forecasting 31: 238-252.

Bernard JT, Khalaf L, Kichian M, Yelou C. 2016. Oil price forecasts for macroeconomic projections: expert outlook, models, or both? Working paper, Carleton University. Macroeconomic Dynamics (forthcoming).

Borenstein S, Kellogg R. 2014. The incidence of an oil glut: who benefits from cheap crude oil in the Midwest? Energy Journal 35: 15-33.

Borenstein S, Shepard A. 2002. Sticky prices, inventories, and market power in wholesale gasoline markets. RAND Journal of Economics 33: 116-139. 
Box GEP, Jenkins GM. 1970. Time Series Analysis, Forecasting and Control. Holden Day: San Francisco, CA.

Busse M, Knittel CR, Zettelmeyer F. 2012. Who is exposed to gas prices? How gasoline prices affect automobile manufacturers and dealerships. NBER Working Paper No. 18610.

Busse M, Knittel CR, Zettelmeyer F. 2013. Are consumers myopic? Evidence from new and used car purchases. American Economic Review 103: 220-256.

Chan JCC. 2013. Moving average stochastic volatility models with application to inflation forecast. Journal of Econometrics 176: 162-172.

Chan JCC, Jeliazkov I. 2009. Efficient simulation and integrated likelihood estimation in state space models. International Journal of Mathematical Modelling and Numerical Optimization 1: 101-120.

Chen SS. 2014. Forecasting crude oil price movements with oil-sensitive stocks. Economic Inquiry 52: 830-844.

Christoffersen P, Diebold FX. 1998. Cointegration and long horizon forecasting. Journal of Business and Economic Statistics 16: 450-458.

Clark TE, McCracken M. 2013. Advances in forecast evaluation. In Handbook of Economic Forecasting, Vol. 2, Elliott G, Timmermann A (eds.). North-Holland: Amsterdam; 1107-1201.

Clark TE, West KD. 2007. Approximately normal tests for equal predictive accuracy in nested models. Journal of Econometrics 138: 291-311.

Diebold FX, Kilian L. 2000. Unit root tests are useful for selecting forecasting models. Journal of Business and Economic Statistics 18: 265-273.

Diebold FX, Mariano R. 1995. Comparing predictive accuracy. Journal of Business and Economic Statistics 13: 253-263.

Edelstein P, Kilian L. 2009. How sensitive are consumer expenditures to retail energy prices? Journal of Monetary Economics 56: 766-779.

EIA. 2014. What drives U.S. gasoline prices? US Department of Energy, US Energy Information Administration, October 2014.

Faust J, Wright JH. 2013. Forecasting inflation. In Handbook of Economic Forecasting, Vol. 2, Elliott G, Timmermann A (eds.). North-Holland: Amsterdam; 2-56.

Giacomini R, Rossi B. 2010. Forecast comparisons in unstable environments. Journal of Applied Econometrics 25: 595-620.

Giacomini R, White H. 2006. Tests for conditional predictive ability. Econometrica 74: 1545-1578.

Giannone D, Lenza M, Primiceri G. 2015. Prior selection for vector autoregressions. Review of Economics and Statistics 97: 436-451.

Gilbert R, Hastings J. 2005. Market power, vertical integration and the wholesale price of gasoline. Journal of Industrial Economics 53: 469-492.

Hamilton JD. 2009. Causes and consequences of the oil shock of 2007-08. Brookings Papers on Economic Activity 1: 215-259.

Hendry DF, Hubrich K. 2011. Combining disaggregate forecasts or combining disaggregate information to forecast an aggregate? Journal of Business and Economic Statistics 29: 216-227.

Kahn JA. 1986. Gasoline prices and the used automobile market: a rational expectations asset price approach. Quarterly Journal of Economics 101: 323-340.

Kilian L. 2009. Not all oil price shocks are alike: disentangling demand and supply shocks in the crude oil market. American Economic Review 99: 1053-1069.

Kilian L. 2010. Explaining fluctuations in U.S. gasoline prices: a joint model of the global crude oil market and the U.S. retail gasoline market. Energy Journal 31: 87-104.

Kilian L. 2015. Comment on Francis X. Diebold's 'Comparing predictive accuracy, twenty years later: a personal perspective on the use and abuse of Diebold-Mariano tests. Journal of Business and Economic Statistics 33: 13-17.

Kilian L. 2016. The impact of the shale oil revolution on U.S. oil and gasoline prices. Working paper, University of Michigan. Review of Environmental Economics and Policy (forthcoming).

Kilian L, Murphy DP. 2014. The role of inventories and speculative trading in the global market for crude oil. Journal of Applied Econometrics 29: 454-478.

Kim CJ, Nelson CR. 1999. State Space Models with Regime Switching: Classical and Gibbs Sampling Approaches with Applications. MIT Press: Cambridge, MA.

Langer A, Miller NH. 2013. Automakers' short-run responses to changing gasoline prices. Review of Economics and Statistics 95: 1198-1211.

Li S, Timmins C, von Haefen RH. 2009. How do gasoline prices affect fleet fuel economy? American Economic Journal: Economic Policy 1: 113-137.

Marcellino M, Stock JH, Watson MW. 2006. A comparison of direct and iterated multistep AR methods for forecasting macroeconomic time series. Journal of Econometrics 135: 499-526. 
Mark NC. 1995. Exchange rates and fundamentals: evidence on long-horizon predictability. American Economic Review 85: 201-218.

Pesaran MH, Timmermann A. 2009. Testing dependence among serially correlated multicategory variables. Journal of the American Statistical Association 104: 325-337.

Molloy R, Shan H. 2013. The effect of gasoline prices on household location. Review of Economics and Statistics 95: $1212-1221$.

Sanders DR, Manfredo MR, Boris K. 2009. Evaluating information in multiple-horizon forecasts: the DOE's energy price forecasts. Energy Economics 31: 189-196.

Stock JH, Watson MW. 2007. Why has inflation become harder to forecast? Journal of Money, Credit, and Banking 39: 3-33.

Sweeney RL 2015. Environmental regulation, imperfect competition and market spillovers: the impact of the 1990 Clean Air Act Amendments on the U.S. oil refining industry. Working paper, Harvard University.

Timmermann A. 2006. Forecast combinations. In Handbook of Economic Forecasting, Vol. 1, Elliott G, Granger CWJ, Timmermann A (eds.). North-Holland: Amsterdam; 35-196.

Yellen JL. 2011. Commodity prices, the economic outlook, and monetary policy. Speech at the Economic Club of New York, NY, 11 April. 